\title{
The product of proliferation disrupter is concentrated at centromeres and required for mitotic chromosome condensation and cell proliferation in Drosophila
}

\author{
Tibor Török, ${ }^{1}$ Peter D. Harvie, Michael Buratovich, ${ }^{2}$ and Peter J. Bryant ${ }^{3}$ \\ Developmental Biology Center, University of California at Irvine, Irvine, California 92717 USA
}

\begin{abstract}
Homozygosity for a null mutation in the proliferation disrupter (prod) gene of Drosophila causes decreased mitotic index, defects of anaphase chromatid separation, and imperfect chromosome condensation in larval neuroblasts and other proliferating cell populations. The defective condensation is especially obvious near the centromeres. Mutant larvae show slow growth and massive cell death in proliferating cell populations, followed by late larval lethality. Loss of prod function in mitotic clones leads to the arrest of oogenesis in the ovary and defective cuticle formation in imaginal disc derivatives. The prod gene encodes a novel 301-amino-acid protein that is ubiquitously expressed and highly concentrated at the centric heterochromatin of the second and third mitotic chromosomes, as well as at $>400$ euchromatic loci on polytene chromosomes. We propose that Prod is a nonhistone protein essential for chromosome condensation and that the chromosomal and developmental defects are caused by incomplete centromere condensation in prod mutants.
\end{abstract}

[Key Words: Mitosis; centromere; heterochromatin; chromosome condensation]

Received October 30, 1996; revised version accepted December 5, 1996.

The precise transmission of genetic information is ensured by the accurate segregation of chromosomes in mitosis and meiosis. For accurate segregation to occur, the chromosomes must undergo a series of precisely regulated events, including chromosome condensation, kinetochore organization, microtubule attachment, and sister chromatid disjunction. The centromere appears to have a key organizing function in most of the above processes (for review, see Pluta et al. 1995).

The centromere of higher eukaryotes consists of several hundred kilobases of repetitive heterochromatic sequences associated with a disc-shaped protein structure, the kinetochore, which is the site of spindle attachment (Willard 1990). The importance of the kinetochore in mitotic events has long been documented (for review, see Sluder 1990), but on the other hand the enormous amount of repetitive DNA in the centromeric heterochromatin was long considered to be functionless (for review, see Pardue and Hennig 1990). However, recent experiments with Schizosaccharomyces and Drosophila minichromosomes have led to the identification of minimal DNA sequences needed for centromere functions and provided direct evidence that the heterochromatin

Present addresses: ${ }^{1}$ Institute of Genetics, Biological Research Center of the Hungarian Academy of Science, H-6701, Szeged, Hungary; ${ }^{2}$ School of Biology, University of Sussex, Falmer, Sussex, UK.

${ }^{3}$ Corresponding author.

E-MAIL PJBRYANT@UCI.EDU; FAX (714) 824-3571. has indispensable functions both in meiosis and mitosis (Baum et al. 1994; Murphy and Karpen 1995). For instance, the Drosophila minichromosome Dp1187 requires a minimum of $200 \mathrm{~kb}$ of heterochromatic sequences for stable inheritance (Murphy and Karpen 1995 ), and the presence of $1000 \mathrm{~kb}$ of heterochromatin is critical for normal meiotic pairing and homolog disjunction in Drosophila females (Karpen et al. 1996). The central core of a minichromosome centromere in fission yeast also must be surrounded by $50-100 \mathrm{~kb}$ of repeated sequences for completely normal transmission (Clarke 1990).

The presence of heterochromatic sequences is also essential in mitosis. Derivatives of the Drosophila minichromosome $D p 1187$ that show abnormal meiotic chromosome transmission also show a high level of mitotic nondisjunction in neuroblast squashes (Murphy and Karpen 1995). The Drosophila Dp(3;f)Th minichromosome is mitotically unstable because it lacks large heterochromatic blocks around the centromere (Wines and Henikoff 1992). Deletion of all flanking repeats from the central core of fission yeast minimal centromeres also results in mitotic instability (Allshire 1995).

The mere presence of heterochromatic DNA is not sufficient for centromere functions; it also has to be properly organized into a functional centromere by specific proteins. For instance, if the assembly of centromeric repeats is disrupted by microinjection of anti-cen- 
tromeric antibodies (ACA) that affect key protein components of the heterochromatin, kinetochore morphogenesis is inhibited in human cells (Bernat et al.1991). Mutations in the clr4, rik1, and swi6 genes of fission yeast lead to mitotic instability and chromosome loss, apparently by disrupting the higher order folded structure of the centromeric heterochromatin and thereby preventing normal centromere function (Allshire et al. 1995).

The condensation of interphase chromatin into mitotic chromosomes also depends on the function of nonhistone DNA-binding proteins (Earnshaw and Mackay 1994|. Chromosome condensation mutants also commonly display other mitotic abnormalities, indicating that condensation is a prerequisite for subsequent mitotic events. For example, cut mutants of Schizosaccharomyces pombe are defective in chromosome condensation and also show abnormal sister chromatid separation during mitosis (Saka et al. 1994). Chromosome segregation is blocked in Saccharomyces cerevisiae mutants defective for topoisomerase II (DiNardo et al. 1984), which is required for chromosome condensation (Wood and Earnshaw 1990). Sensitive alleles of Responder of Segregation Distorter $\left(R s p^{\mathrm{S}}\right)$ in Drosophila cause both aberrant chromosome condensation and abnormal meiotic segregation during spermiogenesis (Wu et al. 1988).

Current experimental data on mitotic and meiotic chromosome behavior clearly support the view that heterochromatin condensation, sister chromatid cohesion, homologous pairing, kinetochore organization, and proper chromosome segregation are all related, at least in part, because all of these events depend on the functions of heterochromatin-associated nonhistone proteins. The subject of the present paper is proliferation disrupter (prod), a gene in Drosophila encoding a nonhistone chromosomal protein that accumulates at the centromeric heterochromatin especially of the major autosomes. We report the cloning, molecular and genetic characterization of the prod gene, document the association of its protein product with centromeric regions as well as euchromatic sites, and show that the product plays an essential role in mitotic chromosome condensation and segregation.

\section{Results}

\section{Isolation and characterization of the prod mutant}

prod was identified in a systematic P-transposon mutagenesis screen for mutations with overgrowth phenotypes (Török et al. 1993) and was originally called l(2)88/ 10. The prod mutation is caused by a single revertible PlacW insertion in polytene chromosome band 56A. A genetic indication that the insertion results in the null condition for this gene came from crossing prod flies to flies carrying the deficiency $D f(2 R) P 34$ (Doane and Dumapias 1987), which removes the 55E2-56B2,Cl region. The resulting hemizygous larvae showed a developmental and chromosome phenotype (see below) indistinguishable from that of the prod homozygote. Homozygotes of prod die as third-instar larvae after a prolonged 20-day larval period. Twenty-day prod larvae show a striking accumulation of apparently undifferentiated tissue in the head region, around and inside the imaginal discs. This phenotype was recorded in the original description as neoplastic imaginal disc overgrowth, but we show here that the imaginal discs are smaller than normal and that the accumulated tissue mass consists of dead cell fragments and blood cells.

prod mutants show massive cell death in proliferating cell populations

Homozygous prod larvae have a slower growth rate than normal and do not reach full size until $\sim 4$ days after their heterozygous siblings pupariate. At 9 days after egg laying (AEL) the mutant larvae still have tiny, slow-growing and abnormal imaginal discs (Fig. 1, cf. A-D and E-H), with the eye-antenna discs always somewhat larger than the others. Despite the extended larval period the discs seldom reach normal size, and they completely lose their epithelial organization in the aging mutant larvae. Electron micrographs show massive cell death in the imaginal discs of prod homozygotes (Fig. 2B,C). Dead cells and cell fragments accumulate at the basal side of the disc epithelium, and by 9 days AEL blood cells have accumulated around the discs, probably as a response to cell death.

The number of free-floating blood cells drops dramatically in the aging larvae (data not shown), indicating that most blood cells are engaged in phagocytosis around the imaginal discs. Another reason for the low number of blood cells in mutant larvae is the disintegration of the lymph glands, which are the source of blood cells (Shrestha and Gateff 1982). Around 9 days AEL the first pair of lymph gland lobes melanizes (Fig. 1I,J\}. Melanization spreads posteriorly with time, and eventually all of the lobes are melanized and start to disintegrate. Large lymph gland pieces can often be observed in circulation, sometimes nearly blocking the dorsal vessel. Electron micrographs of mutant lymph glands show that this tissue also undergoes intense cell death (Fig. 2, cf. E and D). Differentiated plasmatocytes appear to engulf their dying neighbors in the mutant lymph gland and eventually die themselves, only to be engulfed by others.

The mutant larval brain is slow-growing and smaller than normal (Fig. 1J). By the end of larval life it has acquired an abnormal shape (Fig. $1 \mathrm{~K}$ ) and contributes to the amorphous tissue mass in the head. At 20 days AEL prod larvae show a general disintegration of the internal structures. The larvae have an overall transparent appearance because of severe reduction in the fat body, and the head region is filled with a loose mass of tissue mainly consisting of structureless, fused imaginal discs and the $a b-$ normally shaped brain (Fig. 1K). They die at about this time without pupariating.

In summary, all actively proliferating imaginal tissues appear to be severely affected in the mutant larvae; they all show slow growth and eventually degenerate by massive cell death. The penetrance of the mutant phenotype is $100 \%$, but its expressivity is variable. The degree of melanization as well as the amount of cell death differs 

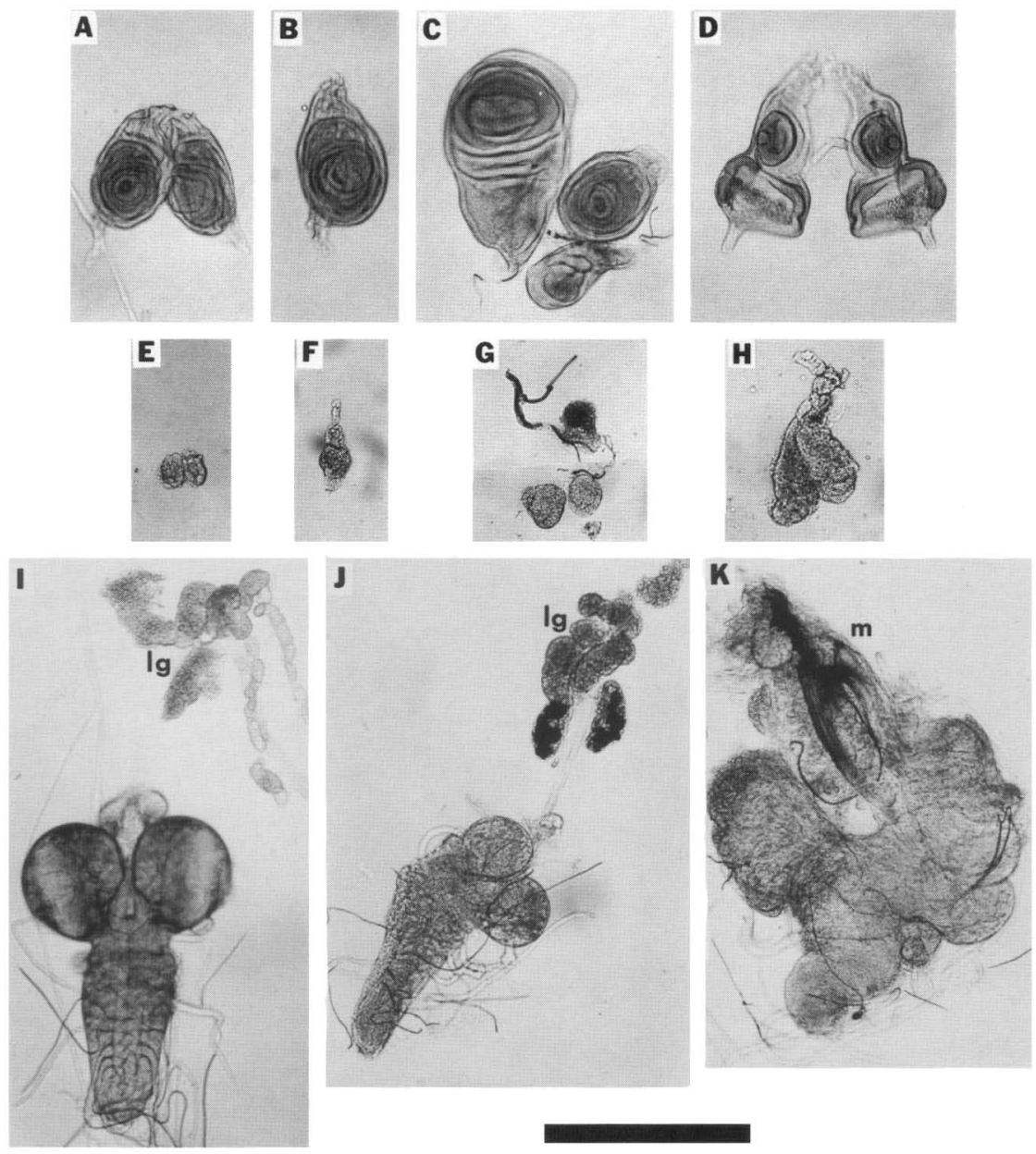

Figure 1. Imaginal discs from wild-type larvae 5 days AEL $(A-D)$ and homozygous prod third-instar larvae 9 days AEL $(E-H)$. $(A, E)$ Pair of first leg discs; $(B, F)$ second leg disc; $(C, G)$ wing, haltere, and third leg disc; $(D, H)$ pair of eye-antenna discs. $\{I, J)$ Brain and lymph glands from wild-type 5 days AEL $(I)$ and homozygous prod third-instar larvae 9 days AEL $(J)$. In $J$, the first pair of lymph-gland lobes $(\mathrm{lg})$ is starting to melanize. $(K)$ Part of the tissue mass dissected from a 20 day prod larval head consisting primarily of distorted brain, fused structureless leg discs, and eye-antenna discs connected to the mouthhook $(\mathrm{m})$. Unstained whole mounts are shown. Scale bar, $0.5 \mathrm{~mm}$. between individuals even at comparable developmental stages and appears to depend on culture conditions, including the level of crowding.

\section{Clonal loss of prod function interferes with oogenesis and cuticle development}

Genetic mosaic experiments were performed to test the requirement for the prod gene product in imaginal disc development as well as in oogenesis. After irradiating prod/ + larvae, we failed to recover homozygous mutant clones on the adults. When prod homozygous clones were induced by irradiating heterozygous prod/Minute larvae to provide a growth-rate advantage to the clones (Morata and Ripoll 1975), marked mutant clones were recovered on the resulting adults but they were smaller and occurred at a much lower frequency than in +/Minute controls. In the few larger clones that were recovered on the legs, the cuticle showed a wrinkled surface and bristles were defective (Fig. 3). The low frequency and small size of homozygous prod clones despite their growth-rate advantage indicates that the gene product is necessary for cell proliferation and/or viability in imaginal discs and that its function is cell-autonomous. The cuticle abnormalities on the larger clones may be a result of cell death within the clone. The survival of smaller clones and occasional larger ones may reflect perdurance of the RNA or protein gene product through several cell divisions after the mitotic recombination event that initiated the clone.

Germ-line mosaic experiments indicate that the Prod protein is also required for oogenesis. When homozygous germ-line clones were induced in heterozygous ovoD1/ prod females using the dominant female sterile technique (Perrimon and Gans 1983), all 535 irradiated females failed to lay eggs. According to the control experiment, $\sim 46$ of the 535 females should have contained prod homozygous germ-line clones. This suggests that oogenesis is arrested in the absence of the prod gene product.

\section{Molecular characterization of the prod gene}

A 6-kb genomic region adjacent to the $\mathrm{P}$ insertion was obtained via plasmid rescue (Wilson et al. 1989), and the DNA was used as probe to screen a genomic library. Finally a $20-\mathrm{kb}$ genomic region around the $\mathrm{P}$ insertion was cloned and restriction mapped (Fig. 4A). Genomic DNA fragments close to the insertion were then used as probes to screen cDNA libraries. A 1563-bp cDNA was isolated from an early embryonic library, and a 1412-bp 
Török et al.

Figure 2. Transmission electron micrographs. (A) Wild-type eye-antenna disc epithelium. $(a)$ Apical disc surface with microvilli; $(b)$ basal surface. $(B, C)$ prod eyeantenna disc 14 days AEL with the same orientation as $A$. Note electron-dense dead cells that tend to accumulate basally. In $C$, the mutant disc is entirely filled inside with dead cell fragments. $(D)$ Wild-type lymph gland with tightly packed, uniformly sized hemocytes. (E) prod lymph gland 14 days AEL. The arrowhead shows the pseudopod of a plasmatocyte engulfing other dying blood cells. Note swollen plasmatocytes full of dead cell fragments. Scale bar, $10 \mu \mathrm{m}$.
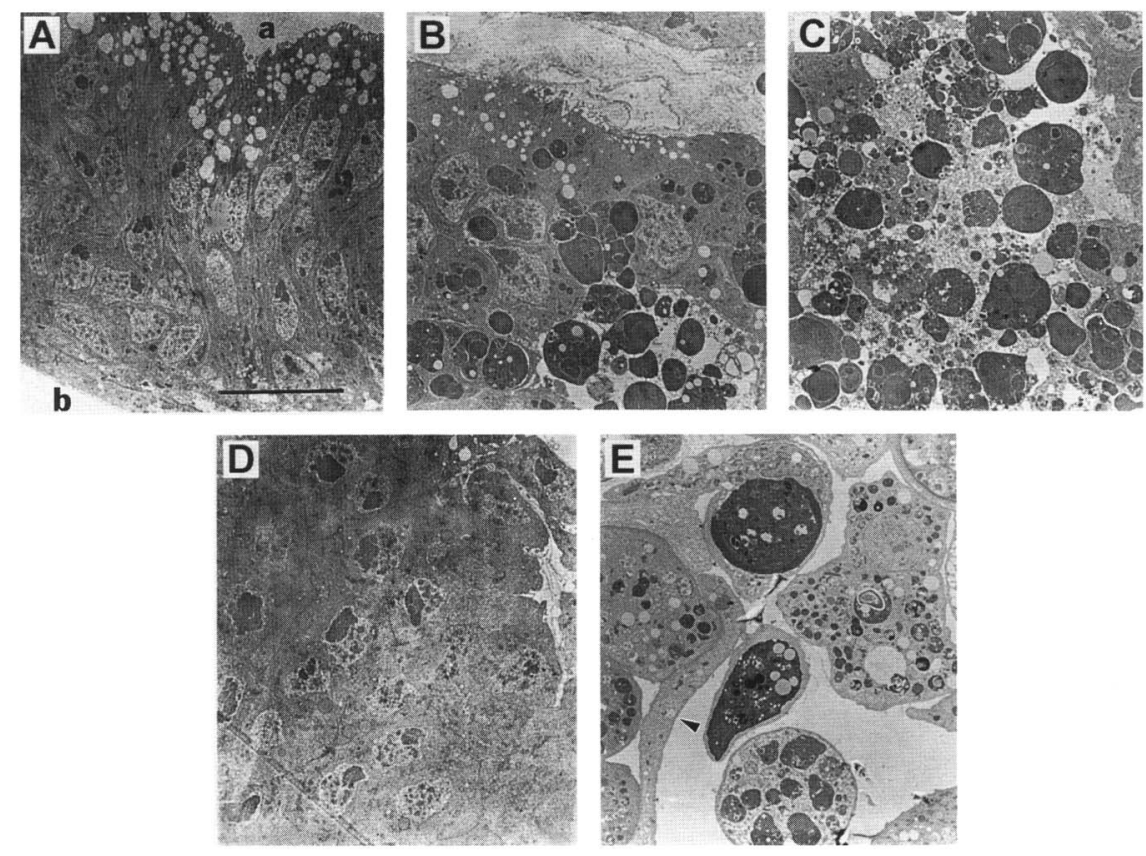

cDNA from a third-instar larval library. Both of these cDNAs and the corresponding genomic DNA fragments were sequenced. The 1412-bp cDNA turned out to be a $5^{\prime}$ truncated copy of the 1563-bp version. The 1563-bp cDNA contains a single large open reading frame $(\mathrm{ORF})$ encoding a novel 301 -amino acid protein (Fig. 4B,C). The translational start site is probably at the second methionine in this ORF, as this site shows higher similarity to the Drosophila consensus translation initiation codon (Cavener 1987) than does the first one. The predicted
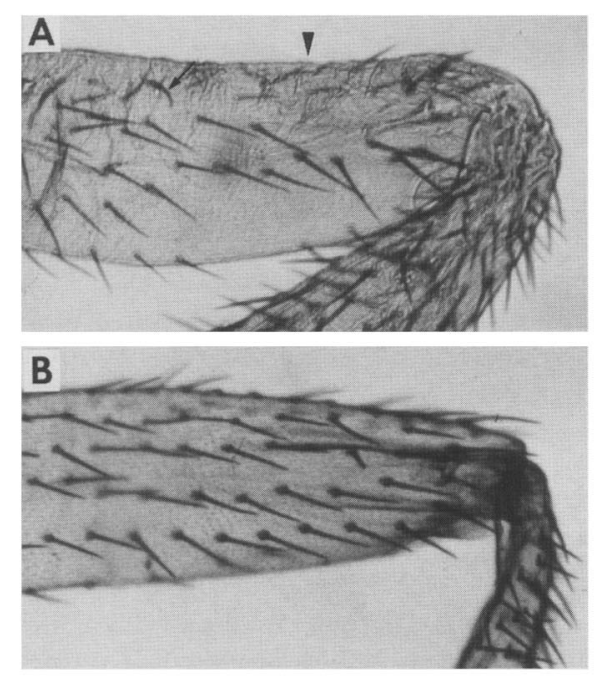

Figure 3. (A) Homozygous prod mosaic clone on femur that extends to the joint. The arrowhead shows a wrinkled cuticle surface where few bristles could be formed. The arrow shows one of the weak forked bristles marking the clone. (B) Wild-type control leg with similar orientation as $A$. protein product is acidic with a $\mathrm{pI}$ of 5.05 , and the sequence shows no significant matches in current sequence databases. The PlacW element is inserted in the $5^{\prime}$-untranslated region of the transcription unit and is

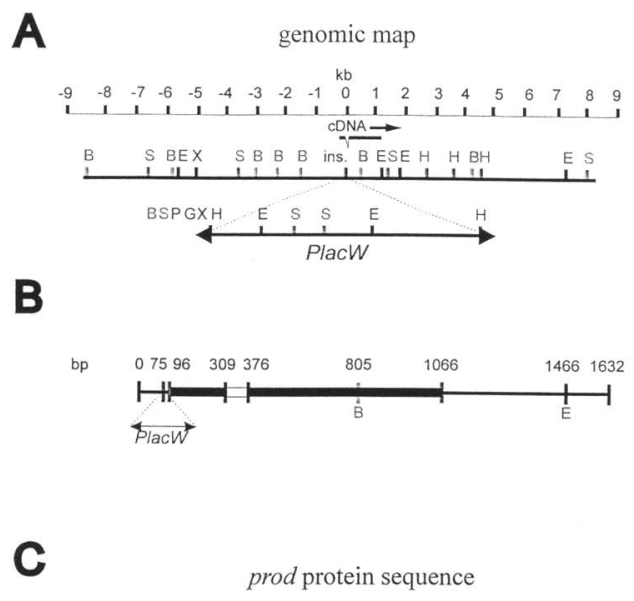
$\begin{array}{lllll}\text { MNGKMDRRKK } & \text { RTSSEQYQMY } & \text { IDMMESDPIF } & \text { ATGRVPRDYD } & \text { LNYLTKKWKE } \\ \text { LSDRLNKCSS } & \text { GPTLTPEEWR KRLNDWKNTT } & \text { RCKYRRSLIS TEKDISMTSV } \\ \text { ETRALDLFGK } & \text { VPTTGGETML NLKSEKDEHD DEMEELGQRT } & \text { SVAFQKELQA } \\ \text { AVEEAINDEV } & \text { DEEEMVEEHV } & \text { DHEDMMEENL } & \text { AETGITASTT } & \text { AVNTGGGTYR } \\ \text { TIVVDNTSFE } & \text { HVEEDPQTVQ PHAVEYVTSR RPAAPVINPG TASSGNKLIN } \\ \text { GELPVKRMRT } & \text { QPREQIIYEV } & \text { KNAPRCISNM } & \text { QAVPPLHSTK } & \text { LEREPSSLTSR }\end{array}$

Figure 4. $(A)$ Restriction map of the genomic region around the prod insertion. (B) BamHI; (E) EcoRI; (G) BgIII; (H) HindIII; (P) PstI; (S) Sall; (X) XhoI. (B) Enlargement from the genomic map showing the prod coding region from the transcriptional start to the stop site. PlacW is inserted in the $5^{\prime}$ untranslated sequence. The solid region represents the 301-amino-acid coding region; open region represents intron sequences. (B) BamHI; (E) EcoRI. (C) Predicted amino acid sequence of the Prod protein. 
thereby predicted to cause an early transcriptional stop (Fig. 4B). The gene contains a single 67-bp intron.

Developmental Northern blots, containing wild-type poly $(\mathrm{A})^{+}$RNA from embryonic, larval, pupal, and adult stages were probed with the isolated cDNAs. The results (not shown) revealed 1.6-kb and 1.4-kb transcripts at all tested stages. The 1.6-kb transcript is expressed highly throughout development, whereas the $1.4-\mathrm{kb}$ transcript is expressed very weakly in all stages except early embryos where it is not detectable. Transformation rescue experiments using cDNA constructs (see below) show that the 1563-bp cDNA is sufficient to perform the prod function.

Northern blots with RNA samples from homozygous mutant larvae and wild-type controls were probed with genomic DNA segments adjacent to the insertion and with the isolated cDNAs. The results revealed that the 1.6-kb transcript and its $1.4-\mathrm{kb}$ shorter version are missing from the mutant (Fig. 5A, lane 3), confirming that the observed phenotype is the null condition for this gene.

We remobilized the PlacW transposon of prod to recover new alleles and small deficiencies by imprecise excision. Only a low frequency of mobilization was achieved, but this produced one small deficiency, $D f(2 R)$ prod- $K$, which removes at least 300 bp from the $5^{\prime}$ end of the prod coding region. Northern blots (Fig. 5A, lane 1) show that the deficiency restores transcription of the gene by removing the PlacW element but makes a truncated version of the transcript. $D f(2 R)$ prod- $K$ is
A

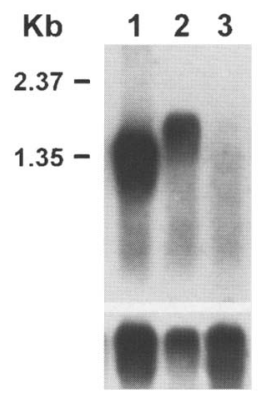

B

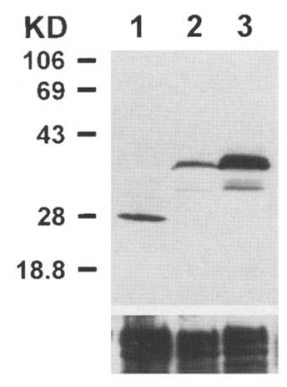

Figure 5. (A) Northern blots of poly(A) $)^{+}$RNA probed with the 1563-bp prod cDNA. The filter was overexposed to reveal any transcripts in the mutant. (Lane 1) Homozygous $D f(2 R)$ prod-K larvae with a truncated transcript; (lane 2) wild type larvae; (lane $3)$ homozygous prod larvae. (Bottom) A control hybridization of the same filter with a $\beta$-tubulin probe. $(B)$ Western blot probed with affinity-purified Prod antibody. (Lane 1) Homozygous $D f(2 R)$ prod-K fly; (lane 2) wild-type fly; (lane 3) transgenic UASprod; hsGal4 fly after a $30-\mathrm{min}$ heat shock at $37^{\circ} \mathrm{C}$. The multiple bands in lane 3 are presumed to reflect multiple translation starts from the transgene. The strongest band that is the same size as the wild-type product in lane 2 probably starts from the second methionine of the largest ORF. This site shows the closest resemblance to the Drosophila consensus translation initiation sequence C/AAAA/C ATG. (Bottom) The same filter probed with anti discs-large antibody (Woods et al. 1996) as a control. weakly viable as a homozygote with a Minute-like phenotype. Thus, the carboxy-terminal half of the Prod protein must be sufficient for almost normal function.

\section{Transformation rescue of the prod mutant}

The 8-kb XhoI-HindIII genomic DNA piece containing the coding region and a $4.5-\mathrm{kb} 5^{\prime} \mathrm{DNA}$ piece with presumed regulatory sequences (Fig. 4A) was cloned into a P-transformation vector and transformed into flies. When chromosomes containing this insert were transferred into a homozygous prod mutant background, the mutant phenotype and lethality were fully rescued, confirming that the entire prod function is contained in this fragment.

We also tried to rescue the mutant phenotype by expressing the prod cDNA with the Gal4/UAS (upstream activating sequence) system (Fischer et al. 1988) in a homozygous prod mutant background. When UAS-cDNA constructs are crossed to different Gal4-expressing lines, the Gal4 protein activates transcription of the cDNA according to the Gal4 expression pattern (Fischer et al. 1988). The 1563-bp cDNA was subcloned into a UAS expression vector and transformed into flies. Antibody staining of Western blots from induced UAS-Prod transformants showed that the protein made from the transgene is the same size as the wild-type Prod protein (Fig. $5 \mathrm{~B}$, lane 3 ), indicating that the entire coding region is present on the transgene.

Of the six different Gal4 lines tested, Gal4 69B gave the best partial rescue of the mutant phenotype, which was a shift from larval to pupal or pharate-adult lethality. These larvae had remarkably normal imaginal discs before pupariation, with only slightly abnormal folding. Gal4 69B is known to induce a high level of expression in imaginal discs during the larval period (Brand and Perrimon 1993).

Surprisingly, UAS-prod expression in a wild-type background was lethal at the embryonic or early larval stages with all of the tested Gal4 lines except hsGal4 (heat-shock Gal4). The slight ubiquitous overexpression caused by the hsGal4 construct without heat shock resulted in prolonged development, weak semisterile adults, and rough eyes. A $30-\mathrm{min}$ heat shock at $37^{\circ} \mathrm{C}$ killed all animals at all tested developmental stages. These experiments suggest that any overexpression of this gene is lethal and that its expression must therefore be regulated strictly and quantitatively.

\section{The Prod protein is localized mainly at the second and third autosomal centromeres and at multiple euchromatic sites}

Polyclonal antisera were prepared from rabbits immunized with a glutathione $S$-transferase (GST)-Prod fusion protein and affinity purified. On Western blots the purified antibodies clearly recognized one strong protein band with approximately the expected molecular weight $(34.3 \mathrm{kD})$ and a very weak smaller band (Fig. 5B, lane 2). It also recognized a smaller version of the protein from 
the homozygous, weakly viable $D f(2 R)$ prod- $K$ allele (Fig. $5 \mathrm{~B}$, lane 1), consistent with the presence of a truncated transcript in these flies. Immunostaining showed that the protein is expressed ubiquitously in embryos, larvae, and adults. The protein shows a characteristic nuclear localization that is modified during the cell cycle.

To follow the distribution of Prod protein through the cell cycle we examined early gastrulae, in which small groups of cells enter mitosis together in mitotic domains (Foe 1989) and most mitotic phases can be observed in close proximity to one another. During mitoses the antibody staining is clearly localized to the centromeric regions of the second and third chromosomes (Fig. 6A,B). On metaphase and anaphase chromosomes this localization is especially obvious, although there is also a weaker staining along all chromosome arms (Fig. 6B, in- set). In prophase (condensing) and telophase (decondensing) chromosomes the main localization remains centromeric, but the extracentromeric staining becomes more dispersed. In interphase the Prod protein is accumulated at the apical nuclear surface, and it also shows a dispersed nuclear staining (Fig. 6C,D). The apical nuclear surface staining probably also represents centromeres, because this interphase arrangement agrees well with the "Rabl orientation" of interphase chromosomes described in early Drosophila embryos (Ellison and Howard 1981; Foe and Alberts 1985), where the Hoechst 33258positive condensed AT-rich centromeric heterochromatin is positioned against the apical nuclear envelope. All of the examined proliferating tissues including larval imaginal discs, brains, imaginal nests, ovaries, and testes of both larvae and adults showed a similar nuclear dis-
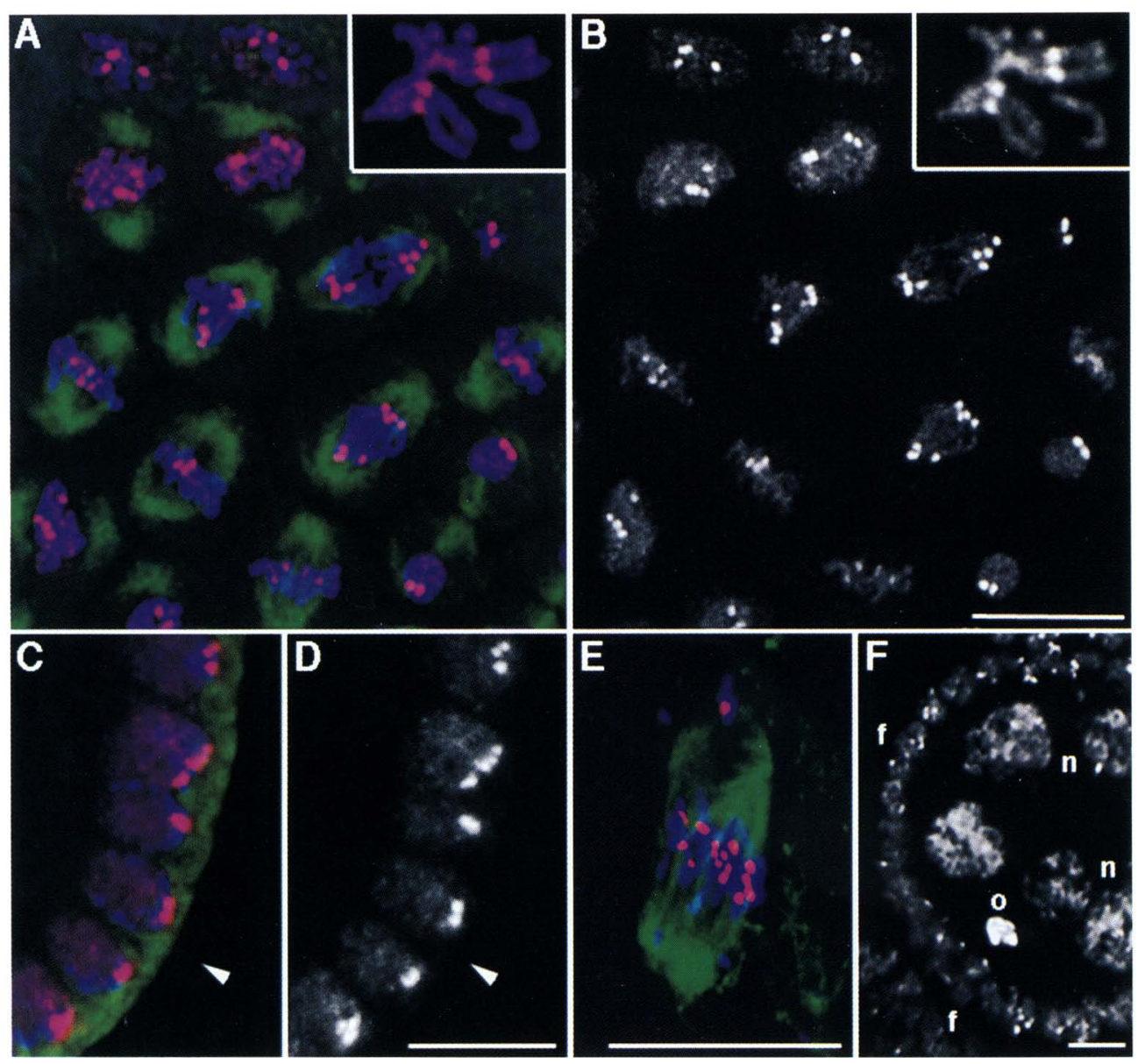

Figure 6. $(A, B)$ Immunostaining of a mitotic domain on a wild-type stage-9 gastrula, showing most mitotic stages. $(C, D)$ Optical cross section of a cellular blastoderm embryo in interphase, showing Prod-positive centromeres at the apical surface of the nuclear envelope. The arrow points to the apical cell surface. $A$ and $C$ are triple stained with $\beta$-tubulin in green (fluorescein), chromosomes in blue (TO-PRO), and Prod-protein in pink/red (Cy3). $B$ and $D$ show only the Prod signal, demonstrating that the protein is also present on chromosome arms. $[A, B$ (inset)] An enlarged chromosome set, where Prod staining is primarily concentrated on the second and third chromosome centromeres. $(E)$ Immunostaining of the first gonomeric mitoses from a freshly layed egg. Note that the spindle is composed of two units and all 16 centromeres are Prod positive. One chromosome (probably the Y) left the metaphase plate earlier. Staining is the same as in $A .(F)$ Optical cross section of a stage 6 egg chamber from a wild-type adult female ovary stained with Prod antibody. The oocyte $(\mathrm{o})$ shows very strong staining compared to the follicle cells $(\mathrm{f})$ and the polytene nurse cells $(\mathrm{n})$. Scale bars, $10 \mu \mathrm{m}$. 
tribution of the protein during the cell cycle. The Prod staining of interphase and mitotic chromosomes of larval neuroblast squashes (see below) was identical to that shown for embryos. However, the first mitotic division in early embryos seems to be exceptional because all four chromosomes show Prod staining (Fig. 6E). This may be because there is Prod protein accumulation during gametogenesis (Fig. 6F), providing an exceptionally high protein level for the first mitotic division. The high protein level in the developing oocyte is also in agreement with germ-line mosaic data, showing the requirement of prod for oogenesis. Chromosomes from prod homozygous larval brain and imaginal disc cells did not show any detectable Prod staining (data not shown) The amount of protein present in the mutant larvae probably diminishes below the level detectable by immunostaining.

On salivary gland polytene chromosomes the antiProd antibody reproducibly stains $>400$ sites including both bands and interbands. However, the chromocenter does not stain (Fig. 7A). Nearly all Prod-positive bands are stained strongly also with DAPI (Fig. 7B,C), suggesting that the protein may preferentially associate with AT-rich regions (Kapuscinski 1995). It probably associates with specific AT-rich structures because not all DAPI-positive bands stain with the Prod antibody. Salivary glands of prod homozygotes are poorly polytenized and do not show any detectable Prod staining.

The prod mutation causes chromosome undercondensation and failure of the metaphaseanaphase transition

The protein localization, the mutant phenotype, and the mosaic data all suggest that the prod gene product has an important role in mitotic cell division. To test the possible role of prod in mitosis we made mitotic chromosome preparations (Gatti and Goldberg 1991) from mutant larvae of different ages. These neuroblast squashes, without colchicine and hypotonic treatment, showed several mitotic abnormalities.

Most obviously, prod tissue shows a significantly lower mitotic index than that seen in wild type. The number of cells in mitosis per microscopic field in the mutant at 5 days AEL (0.1) was less than half the number seen in wild type (0.26). This value decreased in aging larvae, so that in 2-week-old mutant larvae hardly any mitotic cells could be found.

A small proportion $(-10 \%)$ of the metaphase figures on untreated preparations showed incomplete condensation at the centromere (Fig. 8B,C) reminiscent of the phenotype of some chromosome condensation mutations in Drosophila (Gatti and Baker 1989). To better examine the chromosome morphology we made colcemid- and hypotonically treated preparations, in which a large number of cells accumulate in metaphase, chromosomes are better spread, and sister chromatids often separate (Gatti and Goldberg 1991). On metaphase-arrested preparations the mutant larvae also showed significantly fewer mitotic cells than in wild-type and the abnormal condensation was more pronounced. Mutant chromosome arms were about the normal length but often wider than wild-type or irregularly condensed, whereas centromeric regions were elongated and thinner, apparently because of undercondensation (Fig. 8J,K). Sometimes the elongated centromeric region was so thin that the two chromosome arms seemed to be separated (Fig. 8J, inset). Typically a series of different grades of undercondensation, from normally condensed chromosomes to extensively undercondensed ones, were observed within an
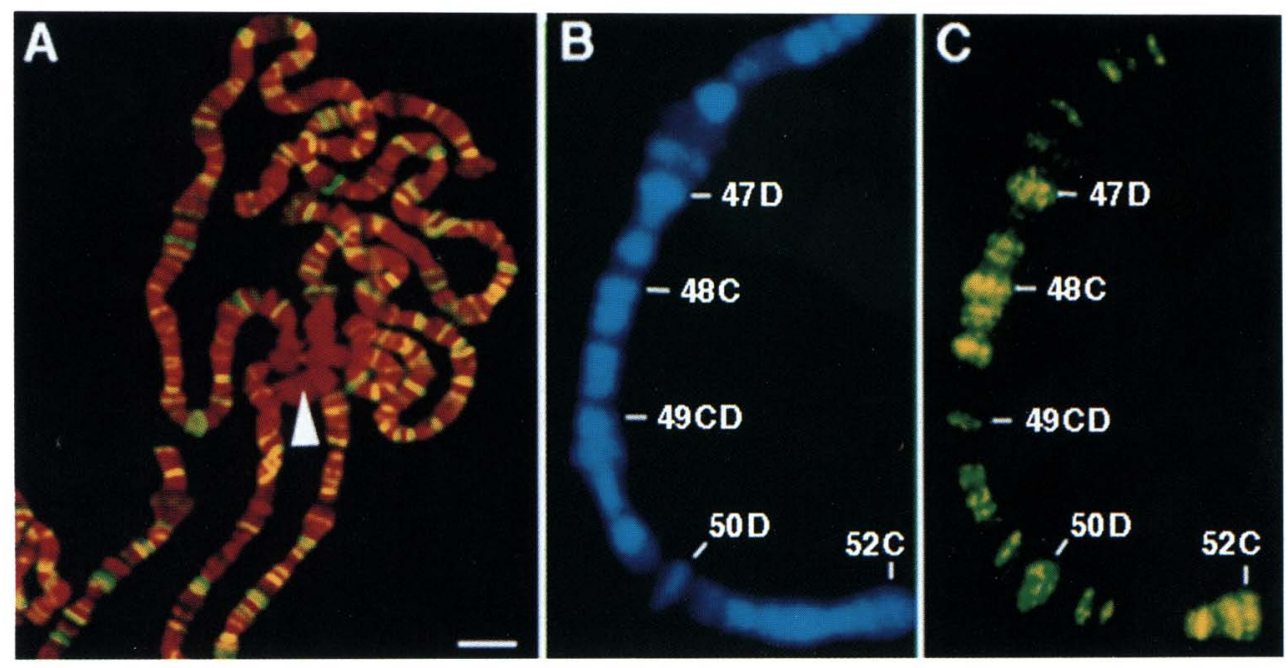

Figure 7. (A) Salivary gland polytene chromosomes stained with Prod antibody. The arrow points to the chromocenter, which is not significantly stained with Prod. Chromosomes were stained red with propidium iodide; Prod staining (fluorescein) is green in interband and yellow in band regions. $(B)$ Enlarged segment of polytene chromosome arm 2R stained with DAPI. $(C)$ Prod staining of the same polytene segment as $B$. Nearly all Prod-positive regions are also strongly stained with DAPI. Scale bar, $10 \mu \mathrm{m}$. 


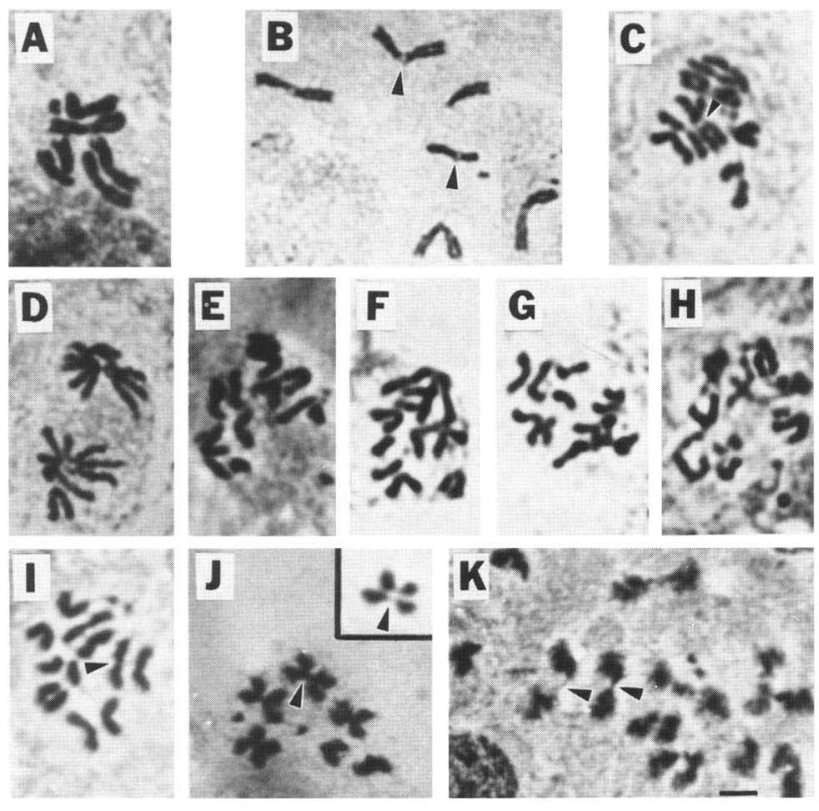

Figure 8. Neuroblast squashes from 5 day wild-type $(A, D, I)$ larval brains and 5 day homozygous prod $(B, C, E-H, J, K)$ larval brains. Samples $A-H$ were untreated; $I-K$ were treated with colcemid and hypotonic solution before squashing. $(A)$ Wild-type metaphase with well condensed centromeres. $(B, C)$ prod metaphase chromosomes with poorly condensed centromeres (arrowheads). Most sister chromatids in $C$ show abnormal separation. $(D)$ Wild-type anaphase. $(E)$ Near normal anaphase from prod brain, with lagging chromatids. $(F-H)$ Abnormal anaphaselike figures from prod brains. Chromosomes are fully condensed and sister chromatids have separated, but the chromatids are irregularly positioned. The chromosomes in $H$ are scattered and fading. $(I)$ colcemid-treated wild-type chromosomes with sister chromatids separated. The arrowhead shows centromeric constriction. (/) Typical prod chromosome set with wider undercondensed arms and elongated centromeres (arrowhead). Inset shows the same with separated sister chromatids. Compare centromeres on $J$ (inset) with those in $I$. $(K)$ prod chromosomes with extremely undercondensed centromeres (arrowhead) and chromosome arms. Sister chromatids are separated. Scale bar, $2 \mu \mathrm{m}$.

individual larva. The proportion of undercondensed chromosomes also showed a great deal of variation between individuals. In some colcemid-treated preparations about half of the metaphase chromosomes showed signs of undercondensation, whereas in others only a few showed this effect. This variable expressivity of the mitotic phenotype is consistent with the similar variability observed at the developmental level.

Another anomaly in the mutant is that fewer anaphases are seen than in wild-type controls. To measure the anaphase frequency we compared the number of metaphase figures with the number of anaphase figures within an individual from untreated preparations (Gatti and Baker 1989). The metaphase/anaphase ratio was 4.6: 1 (17.9\% anaphase) in wild type, compared with $16: 1$ (5.9\% anaphase) in mutants at 5 days AEL. In making the above calculation only anaphases that appeared normal or nearly normal were taken into account. In the mutant we observed randomly arranged chromosomes with separated sister chromatids (Fig. 8F,G) resembling PSCS (premature sister chromatid separation), where sister chromatids separate precociously, before the onset of anaphase (Miyazaki and Orr-Weaver 1994). The randomly arranged chromosomes sometimes were clearly derived from abnormal anaphases, where subsets of chromosomes apparently were not moving toward the poles (Fig. 8E). In many of the abnormal figures the scattered chromatids had a fading Giemsa staining, probably because they had started to disintegrate (Fig. 8H). Apparently in the mutant only a small proportion of metaphase cells enter anaphase and finish mitosis. Cells with scattered chromatids, unable to complete anaphase, probably undergo cell death.

\section{Discussion}

The chromosomal morphology and the abnormal metaphase and anaphase frequencies in the prod mutant, together with the distribution of Prod protein and the developmental phenotype, suggest that the gene product is required for normal chromosome condensation, segregation, and cell proliferation. The low proportion of mitotic cells due to anaphase failure is consistent with the developmental phenotype, the slow growth of proliferating tissues, and massive cell death. The poorly condensed centromeric heterochromatin observed on mutant centromeres correlates with the absence of Prod protein from these chromosomes. The poor centromere condensation probably interferes with kinetochore organization on prod chromosomes, preventing the onset of normal anaphase. It seems likely that the anaphase failure leads to cell cycle arrest and/or cell death.

\section{Late larval phenotype}

The fact that mutant homozygotes survive to late larval stages suggests either that embryonic and early larval stages do not require Prod or that the product is required at all stages but that mutant homozygotes are supported through early development by gene product (either RNA or protein) deposited in the egg by the heterozygous mother. Work on other Drosophila mitotic mutants has shown that late larval lethality, together with poorly developed imaginal discs, can be indicative of a defect in the cell cycle (Gatti and Goldberg 1991), given maternal rescue through the earlier stages. We have been unable to test the idea of maternal rescue directly because germline clones of mutant cells fail to make eggs and therefore do not produce the progeny that would be needed for such a test. However, the high protein expression in oocytes, the high RNA expression in early embryos, and the same Prod protein localization during early syncytial divisions as in later stages suggest that the protein is also required in early stages and is supplied maternally. This interpretation implies that the gene product is long-lived and persists in the cell over many mitotic cycles to allow embryonic and larval development. The growth of imaginal discs and other proliferating tissues in the larva can 
lead to dilution of the maternal product and therefore would require zygotic expression to prevent the mutant phenotype from developing, as in other known mitotic mutants (Glover 1989; Gatti and Baker 1989). The ability of some homozygous prod mutant mitotic clones to survive for a few rounds of cell division also indicates persistence of the prod gene product.

Maternal rescue may also help to explain the variability of the mutant phenotype, as the maternal product may not be equally distributed between daughter cells during division, leading cells to die at variable times during development. In some individuals this process can lead to dramatic accumulation of dead cells and cell fragments in the larval head, the region of most active cell proliferation, which is further extended by accumulation of phagocytic blood cells and cell fragments that drift from other parts of the body via the circulation.

\section{Protein localization}

We do not yet know whether the Prod protein binds to DNA directly, or indirectly, through other proteins. It does not show homology to known DNA-binding domains, and its acidic pI would be more consistent with binding to other chromosomal proteins or protein complexes. In spite of the concentration of Prod on the major autosomes in most preparations, its function does not appear to be restricted to these chromosomes. Both abnormal centromere condensation and abnormal sister chromatid separation were also observed on $\mathrm{X}$ and $\mathrm{Y}$ chromosomes in the mutant (Fig. 8B,C). Preparations from the first embryonic gonomeric mitosis where all centromeres showed Prod staining (Fig. 7E) also suggest that Prod may have a general function on all centromeres. The high protein concentration on the two major autosomes may represent only a quantitative difference between these chromosomes and the X, Y, and fourth chromosomes, with the smaller amount of protein on the latter chromosomes being sufficient for normal function.

The prod gene product at centromeric regions is apparently not a component of the kinetochore, as the centromeric staining does not appear to change during the cell cycle, whereas the kinetochore is known to be disassembled during interphase. It is probably a chromosomal protein that interacts with centromeric heterochromatin sequences that remain condensed throughout the cell cycle (Carmena et al. 1993). The lack of centromeric staining in polytene cells also implies an association of the Prod protein with the $\alpha$-heterochromatin, which is highly underrepresented in polytene chromosomes (Gall et al. 1971; Miklos and Cotsell 1990). The strong staining of the second- and third-chromosome centromeres in mitotic cells suggests that the protein might associate with specific $\alpha$-satellite sequences that are more abundant on the heterochromatin of these chromosomes. One of the Hoechst-positive AT-rich satellite repeats (AATAACATAG) is specific for the second and third chromosomes as determined by in situ hybridization (Lohe et al. 1993) and may provide a preferred Prod-binding site.
In addition to its conspicuous concentration at centromeres, Prod is also present at specific sites along the chromosome arms in polytene chromosomes and is seen more diffusely on the arms of mitotic chromosomes. The polytene chromosome staining pattern suggests that the staining pattern seen during diploid interphase may also reflect dispersed staining of chromosomes. It is probably present at the same genomic sites on both mitotic and polytene chromosomes, but the distribution is clearer on polytenes because of their larger size.

The distribution of Prod is consistent with a role for this protein in both centromeric and euchromatin condensation. Drosophila chromosomes are partially decondensed by Hoechst 33258 (Gatti et al. 1976), resulting in a chromosomal phenotype similar to that produced by the prod mutation. Centromere condensation in the mouse is also incomplete in the presence of Distamycin A, which binds to AT-rich centromeric repeats (Radic et al. 1987). These drugs are thought to act by blocking the interaction of condensation-specific proteins with bent AT-rich structures (Radic et al. 1987). The similar staining pattern of Hoechst 33258 and Prod-positive regions on mitotic chromosomes, as well as DAPI and Prod-positive bands on polytene chromosomes, raises the possibility that Prod might act in chromosome condensation by being part of protein complexes associated with some AT-rich DNA structures.

\section{Centromeric Prod function}

The association of Prod protein with the $\alpha$-heterochromatin of major autosome centromeres and the presence of abnormally condensed centromeres in the mutant indicate that the prod gene has an essential function in the condensation of centromeric heterochromatin. There is increasing evidence that functional kinetochore formation requires proper condensation of the centromeric heterochromatin. Microinjection of ACA antibodies causes metaphase arrest by inhibiting kinetochore morphogenesis in human cells (Bernat et al. 1991). ACA antigens (CENP-B in particular) are localized not in the kinetochore itself but in the surrounding heterochromatin. Based on electron microscopy data, Bernat et al. (1991) suggested that ACA antibodies may, prevent proper condensation of the heterochromatin, thereby preventing kinetochore organization. Fission yeast mutations in clr4, rik1, and swib genes lead to mitotic chromosome loss and at the same time alleviate transcriptional repression of genes placed adjacent to the centromere (Allshire et al. 1995). The products of $c l r 4$, rik1, and swi6 genes presumably influence position-effect variegation (PEV) and centromere function by changing the structure of the centromeric heterochromatin.

We propose that the abnormal anaphases in the prod mutants are a direct consequence of incomplete centromere condensation. Proper attachment of spindle microtubules to the chromosomes requires a well-organized kinetochore, and if spindle attachment is abnormal, the anaphase transition is arrested by a cell-cycle checkpoint (Li and Nicklas 1995). The scattering of chromatids in 
the abnormal prod anaphases indicates that they are either not attached to the spindle or cannot move along it. However, some of the chromatids do seem to move, and the Prod protein does not localize to the spindle apparatus, suggesting that it is spindle attachment rather than spindle formation that is impaired in the prod mutant. Although many of the abnormal prod anaphase-like chromosomes seem to be properly condensed, it is possible that undercondensation that is not discernible by light microscopy is nevertheless recognized as abnormal by the cytokinetic machinery. Weak inhibition of topoisomerase II activity also results in abnormal anaphases and cell death in Drosophila embryos, whereas stronger inhibition causes visible chromosome undercondensation (Buchenau et al. 1993).

The separated sister chromatids in prod mutants are reminiscent of the PSCS phenotype. In other known mutations with a PSCS phenotype the association of chromatids with spindles is random, leading to aneuploid divisions (Kerrebrock et al. 1992; Miyazaki and OrrWeaver 1992; Rockmill and Roeder 1994), but chromosome movement is not affected. However, aneuploid nuclei have not been observed in prod chromosome squashes, suggesting that cells with abnormal anaphases seldom survive until the next division. The lack of aneuploidy and the scattered arrangement of sister chromatids in prod mutants distinguishes the prod phenotype from the known PSCS phenotype. Sister chromatids of ACA-injected human cells eventually also disjoin and display "scattered anaphase" figures (Bernat et al. 1990).

\section{Euchromatic Prod function}

The reproducible distribution of Prod-positive sites on polytene chromosomes and the undercondensation of chromosome arms observed in the mutant indicate that Prod is also necessary for the condensation of euchromatin as well as heterochromatin. Assuming that the distribution of Prod on mitotic chromosomes is similar to that seen on polytene chromosomes, it seems likely that the protein contributes to one of the final levels of euchromatin folding (Manuelidis and Chen 1990) by organizing megabase-sized pieces of DNA.

Many of the known genes whose products have a distinct chromosomal distribution are involved in gene regulation. For example, the products of the Polycomb group genes bind to the regulatory sequences of some 60 other genes (Paro 1990). Some modifiers of PEV also bind to the chromocenter and many discrete loci on polytene chromosomes (James et al. 1989; Garzino et al. 1992). The Trithorax-like (Tr1) gene that encodes the GAGA factor is both an enhancer of PEV and is required for normal homeotic gene expression (Farkas et al. 1994). The $T r l$ gene is remarkably similar to prod in many respects. Its protein product is localized at the centromeric region of Drosophila mitotic chromosomes throughout the cell cycle (Raff et al. 1994) and many euchromatic loci on polytene chromosomes (Tsukiyama et al. 1994). Null mutants of $\operatorname{Trl}$ are late larval lethal with small imaginal discs, and weak alleles are semisterile with re- duced viability and rough eyes (Farkas et al. 1994), very similar to the prod weak overexpression phenotype. $T r 1$ is also required for mitoses, as chromosome segregation and condensation defects were observed in $\operatorname{Trl}$ mutants (Bhat et al. 1996). The GAGA factor activates transcription by binding to the promoter regions of many genes and helping to keep the chromatin structure accessible to RNA polymerase (O'Brien et al. 1995).

These results raise the possibility that the prod mutation may also have an effect on gene regulation. A preliminary test shows that the prod mutation is not a modifier of PEV (data not shown). However, the defects of differentiation in mitotic clones of prod and the abnormalities caused by Prod overexpression may be explained more easily by an effect on gene regulation than by direct chromosomal effects. We cannot therefore exclude the possibility that Prod is also involved in gene regulation, as are other proteins that influence chromosome structure.

\section{Methods}

\section{Isolation of deletions by imprecise excision}

The PlacW insert was remobilized by crossing y $w$; prod/CyO females to $C y O / S p$; Sb $\Delta 2,3 / T M 6$ males. y $w ; C y O / p r o d$; $S b \Delta 2,3 /+$ males from the progeny were crossed to $y w ; C y o / S c o$ females. White-eyed yw; Cyo/Df(2R)prod? males having lost the $W^{+}$marker of PlacW were backcrossed individually to $y w$; $\mathrm{CyO} /$ prod females. If no viable $\mathrm{Cy}^{+}$progeny were found in the next generation because of imprecise excision, a stock was established and the line subjected to Southern blot analysis to detect changes in the prod coding region.

\section{Mosaic experiments}

Somatic mosaic experiments were carried out using the Minute technique, in which the mutant clones are Minute ${ }^{+}$in a Minute heterozygous background and therefore have a growth rate advantage (Morata and Ripoll 1975). y f foa $/ y f^{\delta 6 a} ; f^{+} 44 f^{+} 52 M(2) I^{2} /$ $\mathrm{CyO}$ homozygous forked mutant females that had two insertions of the forked ${ }^{+}$gene on $2 \mathrm{R}$, and the $M(2) I^{2}$ mutation on the same chromosome arm balanced with $\mathrm{CyO}$ (provided by A. Garcia-Bellido/ were crossed to prod/CyO males. Timed egg collections were made at $4 \mathrm{hr}$ intervals and the resulting larvae irradiated with $1000 \mathrm{R}$ of $\gamma \mathrm{rays}$ at $48 \mathrm{hr}$. The non-CyO y $f^{\delta 36 a} / \mathrm{Y}$; prod $/ f^{+} 44 f^{+} 52 M(2) I^{2}$ male progeny were mounted in euparal for microscopy. Control experiments were done with wild-type Oregon- $\mathrm{R}$ chromosomes instead of prod. Mosaic experiments in a wild-type (non-Minute) background were done the same way as above, except the $2 \mathrm{R}$ forked insertion-bearing chromosome did not carry the Minute mutation.

The germ-line mosaic experiment was carried out using the dominant female sterile technique (Perrimon and Gans 1983). Balanced prod females were crossed to males carrying insertions of the dominant female sterile mutation ovoD1 at $2 \mathrm{R}$ (Chou et al. 1993). Timed egg collections were made at 4-hr intervals, and the resulting larvae irradiated with $1200 \mathrm{R}$ of $\gamma \mathrm{rays}$ at $70-74 \mathrm{hr}$ AEL. ovoD1/prod virgins were crossed to Oregon-R males in groups of 15 and checked for progeny. Oregon-R chromosomes were used as controls.

\section{P-transformation and phenotypic rescue}

An 8-kb HindIII-Xhol fragment from the genomic $\lambda$ clone (Fig. 
4) was subcloned into the EcoRI-Xhol site of the PUAST Ptransformation vector (Brand and Perrimon 1993) with a $W^{+}$ marker. The 1.5-kb NotI-XhoI fragment of the pBluescript $(\mathrm{SK})^{-}$ vector containing the 1563-bp cDNA was also subcloned into the Not-Xho site of the PUAST vector. Plasmid DNA was purified on Qiagen 500-tip affinity columns (Qiagen, Inc.). P transformation was done according to Park and Lim \{1995).

\section{Larval neuroblast squash preparations}

Preparations were made as described in Protocol 3 of Ashburner (1989) without Na citrate treatment and stained with Giemsa. In the colcemid-treated preparations, ganglia were incubated in $0.7 \% \mathrm{NaCl}$ containing $10 \mu \mathrm{g} / \mathrm{ml}$ of colcemid (Molecular Probes, Inc.) for $1.5 \mathrm{hr}$ and $0.5 \% \mathrm{Na}$ citrate for $10 \mathrm{~min}$ prior to fixation. Mitotic index was determined as the number of cells with visible mitotic chromosomes per microscopic field. The field was defined as the area visible with a $100 \times$ Zeiss objective and $10 \times$ eyepieces. For determining the metaphase/anaphase ratio, at least 300 fields were counted from $30 \mathrm{prod} / \mathrm{prod}$ or $\mathrm{prod} /+$ individuals.

\section{Nucleic acid procedures}

Standard nucleic acid protocols (Sambrook et al. 1989) were used throughout the study unless otherwise noted. Genomic DNA fragments next to the PlacW element (Bier et al. 1989) were isolated by plasmid rescue: DNA from heterozygous prod flies was digested with $B g I I$, self-ligated, and transformed into XL-1 blue-competent cells. The rescued clones were restriction mapped and used as a probe for screening a $\lambda$ EMBL4 genomic library and two cDNA libraries made in Lambda ZAPII vectors. Bluescript vectors containing cDNA clones were excised from Lambda ZAPII phages with the help of Stratagene Lambda ZAPII Vector Kit. Genomic DNA pieces were subcloned from $\lambda E M B L 4$ into Bluescript for sequencing. Both genomic and cDNA clones were subjected to double-stranded PCR sequencing with the double-stranded DNA Cycle Sequencing System of GIBCO BRL using a series of 15 - to 18 -mer oligonucleotide primers.

Total RNA was purified with the TRIzol reagent of GIBCO BRL. Poly $(A)^{+}$RNA was affinity purified by the poly $(A T)$ tract mRNA isolation system of Promega, electrophoresed $(2 \mu \mathrm{g} /$ lane) on $1.0 \%$ agarose $/ 0.66 \mathrm{~m}$ formaldehyde gels, transferred with $20 \times$ SSC to positively charged nylon membrane (Amersham), UV cross-linked, and hybridized at $42^{\circ} \mathrm{C}$ in $50 \%$ formamide with random primed ${ }^{32} \mathrm{P}$-labeled probe (Stratagene PrimeIt kit).

\section{Fusion protein and antibody production}

The 1526-bp EcoRI fragment containing the entire coding region from the 1563-bp cDNA clone was subcloned into the EcoRI site of pGEX-4T-2 vector (Pharmacia). Cells carrying this construct were induced, harvested, and lysed according to the company's protocol. Fusion protein was purified from inclusion bodies by two rounds of PAGE and sent for antibody production to Pocono Rabbit Farm and Laboratory, Inc. (Canadensis, PA).

The 850-bp BamHI-XhoI fragment containing the $3^{\prime}$ half of the cDNA was also subcloned into pGEX-4T-2, induced, harvested, and fusion protein purified as described above. Antiserum was affinity purified with the pGEX-850-bp fusion protein, using Affi-Gel 15 (Bio-Rad) and following the company's protocol. Remaining background activity was removed from the affinity-purified antibody with a subtraction column containing whole protein extract from homozygous prod larvae bound to Affi-Gel 15.

\section{Antibody staining}

Embryos were collected at $25^{\circ} \mathrm{C}$ on apple juice-agar plates, rinsed in water, and dechorionated for $90 \mathrm{sec}$ in $50 \%$ commercial bleach solution. Taxol pretreatment, fixation, and devitellinization were done as described in Karr and Alberts (1986); then the embryos were rinsed twice in PBS for $5 \mathrm{~min}$ and blocked in $2 \% \mathrm{BSA}, 0.2 \% \mathrm{MP} 40$, and $0.02 \%$ sodium azide in $1 \times$ PBS for $2 \mathrm{hr}$. Purified primary antibody was diluted 1:1000; anti- $\beta$-tubulin $\mathrm{AB}$ (Boehringer Mannheim $\mathrm{GmbH}$ ) was diluted 1:200 in the above blocking solution and incubated with the embryos at $4^{\circ} \mathrm{C}$ overnight. The embryos were washed in blocking solution $4 \times 15 \mathrm{~min}$, incubated with fluorescein or Cy3coupled secondary antibodies (Jackson ImmunoResearch Laboratories Inc.), diluted 1:200 in blocking solution for $2 \mathrm{hr}$ at room temperature, and washed $4 \times 15 \mathrm{~min}$ in the same solution. Chromosomes were stained with $1 \mathrm{~mm}$ TO-PRO (Molecular Probes) in $1 \times$ PBS for $2 \mathrm{hr}$ and washed $4 \times 15 \mathrm{~min}$ in $1 \times$ PBS at room temperature. The embryos were then mounted in Vectashield mounting medium (Vector Laboratories) for confocal microscopy. They were viewed at $60 \times$ on a Bio-Rad 1024 laser-scanning confocal microscope.

Salivary gland polytene chromosomes were prepared as described in Protocol 24 of Ashburner (1989). After removing the coverslip the slides were immersed in $1 \times$ PBS and stained immediately. Chromosome preps were incubated with $50 \mu \mathrm{l}$ of purified Prod antibody diluted 1:200 in PBS, 2\% BSA, and $0.2 \%$ MP40 for $1 \mathrm{hr}$ under coverslip and washed in $1 \times$ PBS, $0.2 \%$ MP40, for $3 \times 5 \mathrm{~min}$. Slides were then incubated with $50 \mu \mathrm{l}$ fluorescent secondary antibody, diluted 1:200 in the above solution for $30 \mathrm{~min}$ at room temperature, and washed again for $3 \times 5 \mathrm{~min}$. Preparations were stained in $1 \mu \mathrm{g} / \mathrm{ml}$ of 4', 6-diamidino-2-phenylindole (DAPI) (Sigma Chemical Co.) or $15 \mu \mathrm{M}$ propidium iodide (Molecular Probes) for $1 \mathrm{~min}$, covered with Vectashield mounting medium under coverslip, and examined with fluorescence microscopy or confocal microscopy.

\section{Electron microscopy}

Lymph glands and imaginal discs of mutant and Oregon-R control larvae were dissected in PBS and fixed in $2 \%$ glutaraldehyde $1 \times$ PBS. The tissue was washed several times in $0.1 \mathrm{M}$ cacodylate buffer containing $8 \%$ sucrose and postfixed in osmium tetroxide, stained with lead citrate and uranyl acetate, embedded in plastic, and sectioned for transmission electron microscopy.

\section{Acknowledgments}

We thank members of the Bryant laboratory, especially Dan Woods, Harald Biessmann, Marika Walter, and Mike Boedigheimer for technical advice and fruitful discussions. The Gal4 lines were provided by N. Perrimon. A 0 - to $24-\mathrm{hr}$ embryonic library was provided by Carl S. Thummel, and a third-instar larval library was given by Rudi Grams. A chromosome carrying two insertions of the forked ${ }^{+}$gene on $2 \mathrm{R}$ and the $M(2) I^{2}$ mutation on the same chromosome arm was provided by Antonio GarciaBellido. This investigation was supported by a Long-term Fellowship from the International Human Frontier Science Program (HFSPO) to T.T. (no. LT-213/94) and by grant no. HD02713 from the National Institutes of Health. The nucleotide sequence of prod cDNA has been deposited in Genbank under Accession number U83596. 
The publication costs of this article were defrayed in part by payment of page charges. This article must therefore be hereby marked "advertisement" in accordance with 18 USC section 1734 solely to indicate this fact.

\section{References}

Allshire, R.C. 1995. Elements of chromosome structure and function in fission yeast. Semin. Cell Biol. 6: 55-64.

Allshire, R.C., E.R. Nimmo, K. Ekwall, J.P. Javerzat, and G. Cranston. 1995. Mutations derepressing silent centromeric domains in fission yeast disrupt chromosome segregation. Genes \& Dev. 9: 218-233.

Ashburner, M. 1989. Drosophila: A laboratory handbook. Cold Spring Harbor Laboratory Press, Cold Spring Harbor, NY.

Baum, M., V.K. Ngan, and L. Clarke. 1994. The centromeric $\mathrm{K}$-type repeat and the central core are together sufficient to establish a functional Schizosaccharomyces pombe centromere. Mol. Biol. Cell 5: 747-761.

Bernat, R.L., G.G. Borisy, N.F. Rothfield, and W.C. Earnshaw. 1990. Injection of anticentromere antibodies in interphase disrupts events required for chromosome movement at mitosis. I. Cell Biol. 111: 1519-1533.

Bernat, R.L., M.R. Delannoy, N.F. Rothfield, and W.C. Earnshaw. 1991. Disruption of centromere assembly during interphase inhibits kinetochore morphogenesis and function in mitosis. Cell 66: 1229-1238.

Bhat, K.M., G. Farkas, F. Karch, H. Gyurkovics, J. Gausz, and P. Schedl. 1996. The GAGA factor is required in the early Drosophila embryo not only for transcriptional regulation but also for nuclear division. Development 122: 1113-1124.

Bier, E., H. Vaessin, S. Shepherd, K. Lee, K. McCall, S. Barbel, L. Ackerman, R. Carretto, T. Uemura, E. Grell, et al. 1989. Searching for pattern and mutation in the Drosophila genome with a P-lacZ vector. Genes \& Dev. 3: 1273-1287.

Brand, A.H. and N. Perrimon. 1993. Targeted gene expression as a means of altering cell fates and generating dominant phenotypes. Development 118: 401-415.

Buchenau, P., H. Saumweber, and D.J. Arndt-Jovin. 1993. Consequences of topoisomerase II inhibition in early embryogenesis of Drosophila revealed by in vivo confocal laser scanning microscopy. J. Cell Sci. 104: 1175-1185.

Carmena, M., J.P. Abad, A. Villasante, and C. Gonzalez. 1993. The Drosophila melanogaster dodecasatellite sequence is closely linked to the centromere and can form connections between sister chromatids during mitosis. I. Cell Sci. 105: 41-50.

Cavener, D.R. 1987. Comparison of the consensus sequence flanking translational start sites in Drosophila and vertebrates. Nucleic Acids Res. 15: 1353-1361.

Chou, T.B., E. Noll, and N. Perrimon. 1993. Autosomal P[ovoD1] dominant female-sterile insertions in Drosophila and their use in generating germ-line chimeras. Development 119: 1359-1369.

Clarke, L. 1990. Centromeres of budding and fission yeasts. Trends Genet. 6: 150-154.

DiNardo, S., K. Voelkel, and R. Sternglanz. 1984. DNA topoisomerase II mutant of Saccharomyces cerevisiae: Topoisomerase II is required for segregation of daughter molecules at the termination of DNA replication. Proc. Natl. Acad. Sci. 81: 2616-2620.

Doane, W.W. and F.E. Dumapias. 1987. Deletion limits of the adp, map and nw loci in Drosophila melanogaster. Dros. Inf. Service 66: 49.

Earnshaw, W.C. and A.M. Mackay. 1994. Role of nonhistone proteins in the chromosomal events of mitosis. FASEB I. 8: 947-956.

Ellison, J.R. and G.C. Howard. 1981. Non-random position of the A-T rich DNA sequences in early embryos of Drosophila virilis. Chromosoma 83: 555-561.

Farkas, G., J. Gausz, M. Galloni, G. Reuter, H. Gyurkovics, and F. Karch. 1994. The Trithorax-like gene encodes the Drosophila GAGA factor. Nature 371: 806-808.

Fischer, J.A., E. Giniger, T. Maniatis, and M. Ptashne. 1988. GAL4 activates transcription in Drosophila. Nature 332: $853-856$.

Foe, V.E. 1989. Mitotic domains reveal early commitment of cells in Drosophila embryos. Development 107: 1-22.

Foe, V.E. and B.M. Alberts. 1985. Reversible chromosome condensation induced in Drosophila embryos by anoxia: Visualization of interphase nuclear organization. J. Cell Biol. 100: 1623-1636.

Gall, J.G., E.H. Cohen, and M.L. Polan. 1971. Repetitive DNA sequences in Drosophila. Chromosoma 33: 319-344.

Garzino, V., A. Pereira, P. Laurenti, Y. Graba, R.W. Levis, Y. Le Parco, and J. Pradel. 1992. Cell lineage-specific expression of modulo, a dose-dependent modifier of variegation in Drosophila. EMBO J. 11: 4471-4479.

Gatti, M. and B.S. Baker. 1989. Genes controlling essential cellcycle functions in Drosophila melanogaster. Genes \& Dev. 3: 438-453.

Gatti, M. and M.L. Goldberg. 1991. Mutations affecting cell division in Drosophila. Methods Cell Biol. 35: 543-586.

Gatti, M., S. Pimpinelli, and G. Santini. 1976. Characterization of Drosophila heterochromatin. I. Staining and decondensation with Hoechst 33258 and quinacrine. Chromosoma 57: 351-375.

Glover, D.M. 1989. Mitosis in Drosophila. J. Cell Sci. 92: 137146.

James, T.C., J.C. Eissenberg, C. Craig, V. Dietrich, A. Hobson, and S.C. Elgin. 1989. Distribution patterns of HP1, a heterochromatin-associated nonhistone chromosomal protein of Drosophila. Eur. I. Cell Biol. 50: 170-180.

Kapuscinski, J. 1995. DAPI: A DNA-specific fluorescent probe. Biotechnal. Histochem. 70: 220-233.

Karpen, G.H., M.-H. Le, and H. Le. 1996. Centric heterochromatin and the efficiency of achiasmate disjunction in Drosophila female meiosis. Science 273: 118-122.

Karr, T.L. and B.M. Alberts. 1986. Organization of the cytoskeleton in early Drosophila embryos. J. Cell. Biol. 102: 14941509.

Kerrebrock, A.W., W.Y. Miyazaki, D. Birnby, and T.L. OrrWeaver. 1992. The Drosophila mei-S332 gene promotes sister-chromatid cohesion in meiosis following kinetochore differentiation. Genetics 130: 827-841.

Li, X. and R.B. Nicklas. 1995. Mitotic forces control a cell-cycle checkpoint. Nature 373: 630-632.

Lohe, A.R., A.J. Hilliker, and P.A. Roberts. 1993. Mapping simple repeated DNA sequences in heterochromatin of Drosophila melanogaster. Genetics 134: 1149-1174.

Manuelidis, L. and T.L. Chen. 1990. A unified model of eukaryotic chromosomes. Cytometry 11: 8-25.

Miklos, G.L. and J.N. Cotsell. 1990. Chromosome structure at interfaces between major chromatin types: alpha- and betaheterochromatin. BioEssays 12: 1-6.

Miyazaki, W.Y. and T.L. Orr-Weaver. 1992. Sister-chromatid misbehavior in Drosophila ord mutants. Genetics 132: 1047-1061.

- 1994. Sister-chromatid cohesion in mitosis and meiosis. Annu. Rev. Genet. 28: 167-187.

Morata, G. and P. Ripoll. 1975. Minutes: Mutants of Drosophila 
autonomously affecting cell division rate. Dev. Biol. 42: 211-221.

Murphy, T.D. and G.H. Karpen. 1995. Localization of centromere function in a Drosophila minichromosome. Cell 82: 599-609.

O'Brien, T., R.C. Wilkins, C. Giardina, and J.T. Lis. 1995. Distribution of GAGA protein on Drosophila genes in vivo. Genes \& Dev. 9: 1098-1110.

Pardue, M.L. and W. Hennig. 1990. Heterochromatin: Junk or collectors item? Chromosoma 100: 3-7.

Park, S. and J.K. Lim. 1995. A microinjection technique for ethanol-treated eggs and a mating scheme for detection of germ line transformants. Dros. Inf. Service 76: 187-189.

Paro, R. 1990. Imprinting a determined state into the chromatin of Drosophila. Trends Genet. 6: 416-421.

Perrimon, N. and M. Gans. 1983. Clonal analysis of the tissue specificity of recessive female-sterile mutations of Drosophila melanogaster using a dominant female-sterile mutation Fs(1|K1237. Dev. Biol. 100: 365-373.

Pluta, A.F., A.M. Mackay, A.M. Ainsztein, I.G. Goldberg, and W.C. Earnshaw. 1995. The centromere: Hub of chromosomal activities. Science 270: 1591-1594.

Radic, M.Z., K. Lundgren, and B.A. Hamkalo. 1987. Curvature of mouse satellite DNA and condensation of heterochromatin. Cell 50: 1101-1108.

Raff, J.W., R. Kellum, and B. Alberts. 1994. The Drosophila GAGA transcription factor is associated with specific regions of heterochromatin throughout the cell cycle. EMBO T. 13: $5977-5983$.

Rockmill, B. and G.S. Roeder. 1994. The yeast medl mutant undergoes both meiotic homolog nondisjunction and precocious separation of sister chromatids. Genetics 136: 65-74.

Saka, Y., T. Sutani, Y. Yamashita, S. Saitoh, M. Takeuchi, Y. Nakaseko, and M. Yanagida. 1994. Fission yeast cut3 and cut 14, members of a ubiquitous protein family, are required for chromosome condensation and segregation in mitosis. EMBO I. 13: 4938-4952.

Sambrook J., E.F. Fritsch, and T. Maniatis. 1989. Molecular cloning: A laboratory manual, 2nd ed. Cold Spring Harbor Laboratory Press, Cold Spring Harbor, NY.

Shrestha, R. and E. Gateff. 1982. Ultrastructure and cytochemistry of the cell types in the larval hematopoietic organs and hemolymph of Drosophila melanogaster. Dev. Growth Differ. 24: 65-82.

Sluder, G. 1990. Functional properties of kinetochores in animal cells. Curr. Opin. Cell Biol. 2: 23-27.

Török, T., G. Tick, M. Alvarado, and I. Kiss. 1993. P-lacW insertional mutagenesis on the second chromosome of Drosophila melanogaster: Isolation of lethals with different overgrowth phenotypes. Genetics 135: 71-80.

Tsukiyama, T., P.B. Becker, and C. Wu. 1994. ATP-dependent nucleosome disruption at a heat-shock promoter mediated by binding of GAGA transcription factor. Nature 367: 525532.

Willard, H.F. 1990. Centromeres of mammalian chromosomes. Trends Genet. 6: 410-416.

Wilson, C., R.K. Pearson, H.J. Bellen, C.J. O'Kane, U. Grossniklaus, and W.J. Gehring. 1989. P-element-mediated enhancer detection: An efficient method for isolating and characterizing developmentally regulated genes in Drosophila. Genes \& Dev. 3: 1301-1313.

Wines, D.R. and S. Henikoff. 1992. Somatic instability of a Drosophila chromosome. Genetics 131: 683-691.

Wood, E.R. and W.C. Earnshaw. 1990. Mitotic chromatin condensation in vitro using somatic cell extracts and nuclei with variable levels of endogenous topoisomerase II. $I$. Cell
Biol. 111: 2839-2850.

Woods, D.F., C. Hough, D.J. Peel, G. Callaini, and P.J. Bryant. 1996. Dlg protein is required for junction structure, cell polarity, and proliferation control in Drosophila epithelia. I. Cell Biol. 134: 1469-1482.

Wu, C.I., T.W. Lyttle, M.L. Wu, and G.F. Lin. 1988. Association between a satellite DNA sequence and the Responder of Segregation Distorter in D. melanogaster. Cell 54: 179-189. 


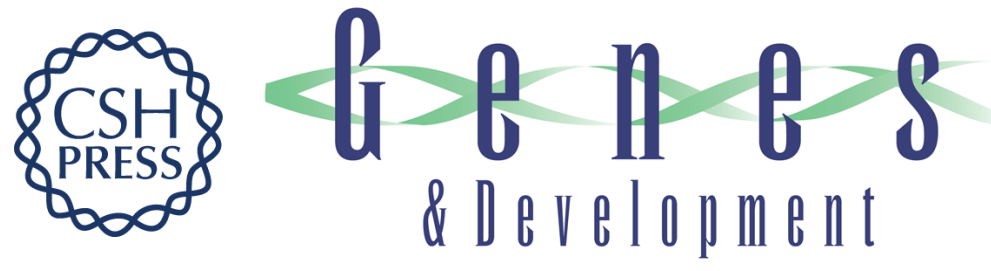

\section{The product of proliferation disrupter is concentrated at centromeres and required for mitotic chromosome condensation and cell proliferation in Drosophila.}

T Török, P D Harvie, M Buratovich, et al.

Genes Dev. 1997, 11:

Access the most recent version at doi:10.1101/gad.11.2.213

References This article cites 60 articles, 27 of which can be accessed free at: http://genesdev.cshlp.org/content/11/2/213.full.html\#ref-list-1

License

Email Alerting Service

Receive free email alerts when new articles cite this article - sign up in the box at the top right corner of the article or click here.

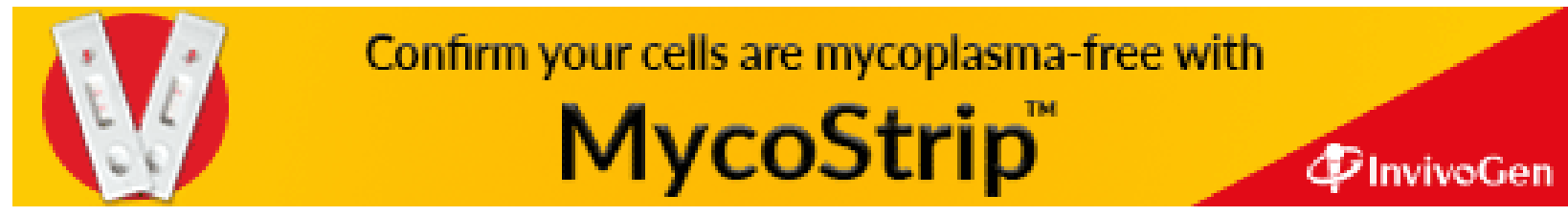

